\title{
The Diminishing Value of Representing the Disadvantaged: Between Group Representation and Individual Career Paths
}

\author{
Stefanie Bailer ${ }^{1}$ (D), Christian Breunig ${ }^{2}$ (D), Nathalie Giger ${ }^{3 \star}$ (D) and Andreas M. Wüst ${ }^{4}$ (D) \\ ${ }^{1}$ University of Basel, Switzerland, ${ }^{2}$ University of Konstanz, Germany, ${ }^{3}$ University of Geneva, Switzerland and ${ }^{4}$ University of \\ Stuttgart, Germany \\ ${ }^{*}$ Corresponding author. E-mail: nathalie.giger@unige.ch
}

(Received 22 May 2018; revised 6 July 2020; accepted 12 September 2020; first published online 22 February 2021)

\begin{abstract}
Does enhanced descriptive representation lead to substantive representation? Legislators who share descriptive features with disadvantaged groups do not necessarily represent their group interests. Instead, Members of Parliament (MPs) strategically choose when to engage with the policy topic of their corresponding groups. MPs represent their respective group at the beginning of their career because it confers credibility when they have no legislative track record and few opportunities to demonstrate expertise. These group-specific efforts are replaced by other legislative activities at later stages of their careers. The authors apply this theoretical expectation across four disadvantaged groups - women, migrants, low social class and the young - and thereby offer a broad perspective on descriptive representation. Their sample consists of a unique data base that combines biographical information on German MPs with topic-coded parliamentary questions for the period 1998 to 2013. The study demonstrates the diminishing value of representing the disadvantaged across different types of MPs.
\end{abstract}

Keywords: descriptive representation; substantive representation; minority representatives; German Bundestag

Growing evidence of unequal representation (for example, Bartels 2009; Carnes 2013; Gilens 2012; Hacker and Pierson 2010) raises important questions about how representative democracy works. One particular concern is that sparse descriptive representation of disadvantaged groups ${ }^{1}$ in parliament and government may lead to unequal substantive or policy-related representation of certain societal groups (Carnes and Lupu 2015; Childs and Lovenduski 2013; Mansbridge 1999; Saalfeld 2011). This concern has led political scientists to examine the social background of elected representatives and its consequences. The central question is: does the enhanced representation of disadvantaged groups in parliament lead to a better substantive representation of the group members' interests?

Prior studies on the effects of descriptive representation predominately explore whether descriptive representation enhances the substantive representation of disadvantaged interests in national assemblies. The current literature offers an aggregate- and individual-level-perspective. We adhere to an individual perspective (see also Carnes 2013; Davidson-Schmich 2016;

\footnotetext{
${ }^{1}$ We use the term 'disadvantaged group' following Mansbridge (1999). Occasionally, we employ the term 'minority' or 'under-represented' as we focus on the lower level of representation of these groups in parliament compared to their share of the population. We are aware that these terms are slightly different conceptually, but all three are frequently used in the pertinent literature.

(C) The Author(s), 2021. Published by Cambridge University Press. This is an Open Access article,distributed under the terms of the Creative Commons Attribution-NonCommercial-ShareAlike licence (http://creativecommons.org/licenses/by-nc-sa/4.0/), which permits non-commercial re-use, distribution, and reproduction in any medium, provided the same Creative Commons licence is included and the original work is properly cited. The written permission of Cambridge University Press must be obtained for commercial re-use.
} 
Greene and O’Brien 2016; Grose 2005; Höhmann 2019; Öhberg and Wängnerud 2013; Breunig and Schnatterer 2016; Gilens 2012; Mansbridge 2015; Minta 2009; Saalfeld and Bischof 2013) and place individual representatives and their incentives for substantive representation at the analytical center.

We posit that substantive representation of disadvantaged groups' interests is not only a function of the number of group members in parliament or government (see, for example, Davidson-Schmich 2016; Hänni 2017; Krook and O’Brien 2010; Preuhs 2006); it also depends on the strategic choices that individual Members of Parliament (MPs) make during the course of their political careers. Given these individual choices, substantive representation of disadvantaged interests varies over time. Focusing on individual MPs and their (strategic) decisions to represent the disadvantaged, we argue that these representational efforts become weaker over time because MPs must eventually choose between group representation and their individual career paths. Representing interests of the group MPs belong to bestows credibility when they have hardly any legislative track record and few opportunities to demonstrate their expertise.

These group-specific activities are likely to decline later in their legislative career for three reasons. First, freshmen legislators learn how to navigate the legislative process over time and eventually settle on a particular legislative style. During this transformation, they often become more effective in their legislative activities (Bailer and Ohmura 2017; Miquel and Snyder 2006) and shift their substantive interests. Secondly, with increasing seniority they are able to establish themselves in other policy areas and garner their colleagues' consent to their engagement in new areas of interest. Finally, experienced legislators are more likely to hold higher positions in their party and in the plenary, and consequently decrease group-specific parliamentary activities (Wüst 2014). The implication of these factors is that substantive and descriptive representation is not constant for MPs from disadvantaged groups; instead, substantive representation varies depending on individual career paths.

This article contributes to the existing literature on representational linkages in two ways. First, we include several common types of group representation in our theory and empirical analysis. Previous studies on representing disadvantaged groups have developed rather independently of each other (for example, studies on the representation of women or ethnic minorities). We add to recent work that examines several under-represented groups at the same time (for example Celis and Erzeel 2013; Celis and Wauters 2010; Lowande, Ritchie and Lauterbach 2019).

Secondly, we identify a common mechanism that is at play across disadvantaged groups and therefore examine four groups - women, lower social class, the young and migrants - simultaneously. This encompassing approach allows us to distinguish among various groups and address whether MPs choose to represent certain groups during the course of their career more generally. We compiled an original data set that combines biographical information on MPs' backgrounds (identifiers for four groups disadvantaged in society) with their parliamentary activities. These activities are topic coded according to the Comparative Agenda project (http://www.comparativeagendas.net). Our analysis encompasses all questions to government (interpellations) for all members of the German Bundestag between 1998 and 2013. Our estimates suggest that descriptive representation leads to substantive representation early in the career of individual MPs; yet this substantive representation decreases as they gain seniority. Our common data base highlights that female MPs depart from this trend: they are more likely than male MPs to represent women's interests throughout their career, but they do so with decreasing intensity over time.

\section{Representing Disadvantaged Groups and Individual Career Paths}

Descriptive representation refers to the idea that parliament is selected in a way that corresponds to characteristics of the population (Pitkin 1967). Descriptive representation is manifest when elected officials 'mirror' the broad spectrum of ascriptive characteristics of the population 
(Mansbridge 2009). Groups of people can be identified based on sex, language, religion, ethnicity, class, nationality, race, caste, age, expatriation, profession, domicile and (dis-)ability (Krook and O’Brien 2010). ${ }^{2}$

Considerable advances toward the goal of a descriptively representative political body can be observed in recent decades. However, parliaments all over the world still are far from mirroring their populations in terms of their descriptive characteristics. For example, in 2016 women constituted about half of the world's population but comprised only 22.6 per cent of all parliamentarians worldwide (Interparliamentary Union 2016). For other groups it is more challenging to assess the level of descriptive representation since the groups in question vary significantly in size and across national contexts (Bird 2003, but see also Ruedin 2013). Scholars generally confirm that most disadvantaged groups are under-represented based on their proportion within society. This assessment is true for ethnic minorities (Ruedin 2009), immigrants and their descendants (Bird, Saalfeld and Wüst 2010), Blacks and Latinos (Preuhs 2006), and lower social classes (Carnes 2013). In recent decades, parliaments have become more biased in their composition on some features, such as top-share incomes (Carnes 2013; Gilens 2012) and more equal on others, such as migrant background (Dancygier et al. 2015).

Descriptive representation is a relevant consideration for democracy from a normative perspective as well as for symbolic reasons (Norris and Lovenduski 1995). An equally important question is whether the presence of disadvantaged groups in parliament ensures the substantive representation of their interests - a fundamental dimension of democratic theory. Addressing this question empirically is not straightforward: one first has to define what the 'group interest' is and then determine what is meant by policy influence.

Is descriptive representation congruous with substantive representation? As we discuss below, existing evidence is variegated at the aggregate level and can be summarized as follows: the descriptive composition of the political body matters in some instances more than in others. Distinguishable preferences between legislators with and without disadvantaged backgrounds persist, yet these differences do not translate directly into distinct legislative outcomes. Substantive evidence tends to become weaker as one moves from various legislative activities to final decisions, such as roll-call votes, which are structured by institutional factors, such as party discipline, to a high degree.

A wide range of studies examines the link between the presence of certain disadvantaged groups and substantive outcomes for a number of minorities. However, the literature provides mixed evidence on the link between descriptive and substantive representation, especially related to the impact of female presence. Bird, Saalfeld and Wüst (2010), Preuhs (2006), and Minta (2009) propound that the representation of ethnic minorities matters substantively, while Kittilson (2008), Lloren (2015), and Bratton and Ray (2002), for example, show that women's representation in parliament enhances substantive representation, while Homola (2019) cannot confirm this link. Finally, Carnes and others (Carnes 2013; Carnes and Lupu 2016; O'Grady 2019) demonstrate that lacking MPs from lower economic strata skews attitudes in parliament.

Collectively, the literature offers a number of potential mechanisms and motivations for linking representatives of disadvantaged groups to substantive interests, ${ }^{3}$ including a large volume of work dedicated to gender. Do all disadvantaged legislators advocate group-specific issues to the same degree? If not, what causes a stronger or weaker link to the group they belong to? Previous studies have not been able to sufficiently address this question because their research designs, on the whole, did not allow for individual variation in motivations and interests since they are typically based on an aggregate comparison of numerical presence and legislative proposals or

\footnotetext{
${ }^{2}$ These are also the groups for which descriptive representation is seen as a desirable component of democracy (Mansbridge 2015).

${ }^{3}$ We employ Pitkin's (1967) definition of representation as 'acting for' and understand parliamentary activities as representational activities. We acknowledge that other aspects of group representation, e.g., policy outcomes in the form of minority language rights, are important too.
} 
outcomes. Therefore, they were unable to undertake a longitudinal and dynamic analysis of legislators' behavior and at least implicitly see motivation among MPs as uniform and time invariant. As a result, prior studies do not distinguish between group interests and individual MPs' interests. We know little about the extent and implications of the changing motivations of politicians to engage in the representation of the group they belong to. ${ }^{4}$

For example, the so-called presence model (Philips 1995; Preuhs 2006) holds that the enhanced presence of disadvantaged MPs should lead to different policy outcomes based on the idea of shared experiences and the common background of MPs and the disadvantaged group. They should therefore 'act as stronger advocates for minority group interests than nonminority legislators' (Preuhs 2006). Philips herself admits in her book that this connection remains 'a shot in the dark' $(1995,83)$ as she is well aware of the constraints that political institutions pose for the advancement of the interests of under-represented groups, women in particular. Subsequent research has thus further explored how political parties and institutional features condition the link between descriptive and substantive representation (Childs and Krook 2009; Hawkesworth 2003; Lublin 1997; Rocca and Sanchez 2007). All in all, prior research recognizes the contingent nature of the link between descriptive and substantive representation. This contingency connotes that an MP's background will not translate into a persistent and continuous representative effort on behalf of their social groups throughout their career.

We add a twist to this literature and contend that representation activities vary throughout individual MPs' electoral careers. ${ }^{5}$ Building on rational choice approaches in legislative politics, we assume that parliamentarians aim to maximize three goals: reselection, re-election, and party and legislative office (Strøm 1997). To achieve these aims, they choose certain roles, which can be understood as 'strategies for the commitment of scarce resources' such as their time, attention or money (Strøm 1997). While rational choice institutionalists analyze how institutional incentives shape the selection of these roles, we utilize role selection as a mechanism that influences strategic choices during parliamentarians' career cycles.

At the beginning of their legislative career, parliamentarians consciously decide which activities to focus on. This commitment involves learning certain skills and rules as well as choosing a policy area in which they are willing to invest resources such as time and attention. Their choice of legislative activity is influenced by endogenous factors such as expertise and interest, as well as strategic considerations related to appearing competent and credible as an MP. Parliamentarians engage in activities that they can credibly represent and in which they have personal experience and thus expertise (Butler 2014). Personal judgements about their ability to completely represent the issues of disadvantaged groups as well as intrinsic motivation drive newly elected MPs to focus on particular policy areas. As German MP Omid Nouripour, who has a migrant background, pointed out: 'It is understandable that integration policy is the natural starting point for us. Many of us experienced discrimination and have the strong desire to change something in that area' (Mutlu 2016, 122). These individual factors may also be shaped by party group leaders or experienced legislative colleagues who are able to narrow the choice of substantive opportunities available to a newcomer and do not want to share more attractive or established policy areas with newcomers.

Within these constraints, individual MPs at the beginning of their career can strategically choose legislative activities that portray them as particularly credible representatives of a given disadvantaged group. Hence, MPs choose to represent a particular group they belong to symbolically because their innate characteristics transmit credibility to both the public and to their

\footnotetext{
${ }^{4}$ The critical actors concept as introduced by Childs and Krook (2009) in their study of women's representation marks a valuable exception, as this concept focuses on individual actors and their varying motivation to represent women.

${ }^{5}$ The concept of 'co-optation', researched in gender studies, describes a rhetoric and discursive practice to absorb, neutralize and overtake the meaning of an original concept to fit to prevailing political priorities and norms (see e.g. de Jong and Kimm 2017; von der Lippe and Väyrynen 2011). This literature often examines the perspective of the system and outside actors and lies beyond $\mathrm{d}$ the scope of our research question.
} 
constituents (Best and Vogel 2014). For example, Greene and O'Brien (2016) show that female representatives act as issue entrepreneurs and are able to address new issues. Collet (2008) shows that when campaigning, minority candidates consciously choose to maximize their chances by representing their minority while not offending other sections of the electorate. Moreover, the public and media often ascribe competence to representatives to disadvantaged in the policy area most closely related to their background, as illustrated by German MP Cem Özdemir: 'I was motivated by my environmental interests to join the Greens and not by migration topics. [...] However, when I spoke about [...] how to protect mountains from climbers, questions about integration, migration, Turkey and Islam were asked. Thus, I enlarged my policy area' (Mutlu 2016, 129).

The influence of party leadership and seniority also affects the type of legislative activities newcomers engage in. New MPs rarely have the opportunity to initiate legislation; they instead tend to focus on activities connected to oversight, such as parliamentary questions. Miquel and Snyder (2006), Schiller (1995), and Bailer and Ohmura (2017) illustrate the impact of career stage on parliamentary activities and show that parliamentarians are less effective, sponsor fewer bills and tend to ask more parliamentary questions. Senior colleagues are tasked with weightier parliamentary activity, such as legislative proposals or rapporteurships.

The process of choosing a legislative activity is not only determined by a strategic choice during the course of a career; party colleagues and party group leaders also play a role. Newcomer MPs seldom have complete freedom to choose which area to engage in, since more established parliamentarians do not necessarily want to share their political expertise and policy specializations (Bolzendahl 2014; Fenno 1962; Osborne 2012). However, a party leader may allow newcomers to actively represent the disadvantaged when the leadership expects benefits from these efforts. Established party colleagues accept that newcomers are active in a policy field related to minorities because voters attribute expertise to the newcomers in these policy fields (Celis, Erzeel and Mügge 2015). A comment by an MP of immigrant origin in the German Bundestag, Ekin Deligöz, illustrates this process:

My attributes - young, female, migration background - were an advantage in the Green party. But when I became a parliamentarian I realized that they thought that I could not do much more than that. [...]. I had to demonstrate that I am more than my background. [...] But when I was talking about migration issues or Turkey everyone was listening. That is a chance but it is also getting reduced to some topics. ${ }^{6}$

During their legislative career, the strategic value of substantive representation for a particular disadvantaged group diminishes. Over time MPs are able to acquire expertise and credibility within parliament. They can employ these assets by dedicating more of their time to new policy fields. As Davidson (1969) suggested, pursuing particular constituency interests becomes less important over the course of legislators' careers. MPs shift their attention towards legislative affairs that require more insider knowledge and professionalization acquired during their mandate. Acquiring new policy expertise is important because it enables MPs with disadvantaged backgrounds to move from representing narrow group interests to making broader political appeals. Cem Özdemir, a German legislator with a Turkish background mentioned above, described this transformation: 'I was fighting against the role assigned to me [...]. If at all I wanted to be a policy expert for all people in Germany, not only for the Germans with migration background' (Mutlu 2016, 133). New interests, especially in the core functions of government, enable MPs to enhance their standing within the party and parliament. In short, shifting from a focus on the substantive representation of disadvantaged interests to a broader legislative agenda enables minority MPs to

\footnotetext{
${ }^{6} \mathrm{http}: / /$ www.spiegel.de/spiegel/spiegelspecial/d-55972863.html, accessed 21 June 2016 and https://www.youtube.com/ watch? $=$ jrEmvXo34ww, Min 41:30 accessed 8 April 2017.
} 
transition into leadership positions. Broadening individual policy portfolios is particularly important for disadvantaged MPs because these legislators differ in their political opportunity structures (for example, access and experience) from their non-minority colleagues (see O’Brien 2015 for gender).

Taken together, we derive two expectations regarding the substantive representation of disadvantaged MPs. First, parliamentarians from disadvantaged groups engage in more legislative activities in their respective policy field than their colleagues. Second, parliamentarians from disadvantaged groups demonstrate a particularly high level of activity at the beginning of their career in their respective issue area, but this level of activity declines during the course of their career.

\section{Empirical Strategy ${ }^{7}$}

Our theoretical expectations require a research design that combines information from two major sources: parliamentary activities in policy domains that reflect an MP's substantive concerns and biographical information about MPs. We construct this database for MPs in the German Bundestag for the period between 1998 and 2013 (fourteenth to the seventeenth legislative session). The Bundestag and its MPs offers a useful sample for five main reasons. First, similar to other professional national parliaments, MPs seek long time careers (average time spent in parliament is 10 years). Secondly, interpellations in Germany place only some institutional constraints on individual legislative action. As is typical for parliamentary democracies, most individual legislative activities in the Bundestag are dominated by strong partisan groups, particularly after recent reforms (Ismayr 2012). Speeches, questions and the signing of interpellations are among the few remaining legislative tools for MPs to represent electoral interests individually (Martin and Rozenberg 2012) and the rights of minorities outside party group pressure (Siefken 2010). Moreover, these legislative tools result in an official document that can be communicated to the media and the public on websites, social media and the press (Siefken 2010), which helps individual MPs claim personal credit for such activities.

Interpellations in Germany provide us with the opportunity to gauge individual effort on a given issue. Interpellations require at least 5 per cent of the members of the Bundestag or a party faction to sign onto a question. Hence, if individual signees sidestep their party faction, they need to assemble the required quota for submission, and may reach across party lines to do so. Circumventing party factions therefore involves substantive costs associated with taking individual legislative action on a particular issue. Although interpellations generally need to be approved by a party group, the lead signatories stand out for taking an initiative and representing a particular group. We therefore can employ individually signed interpellations as a credible tool for signaling an opinion on an issue.

Moreover, interpellations require a government response and force the respective ministry to provide answers. These demands make interpellations and parliamentary questions powerful tools for setting the parliamentary agenda and are thus a springboard for legislation (Green-Pedersen and Mortensen 2010). In short, studying interpellations helps us capture a substantial number of individual representational activities of MPs.

The third advantage of our sample is that in the German mixed electoral system, we are able to directly assess distinct constituency linkages between voters and representatives and the role of electoral systems. Some MPs are directly elected, while others come from partisan lists. Fourthly, the study period is long enough to control for government-opposition dynamics. Five of the six parties in parliament have been in both the government and opposition during this time. Fifthly, the Bundestag is large enough (709 MPs) to encompass a substantial number of various minorities, which renders analyses in smaller parliaments challenging. Below we detail the dependent variable (Interpellations) and then elaborate on substantive group representation

${ }^{7}$ All replication materials are available under https://doi.org/10.7910/DVN/SZGS68. 
among MPs. A discussion of estimation strategy and model specification concludes the research design section.

\section{Parliamentary Questions as Valuable Information for Group Representation}

A core challenge associated with assessing group representation is identifying a legislative activity that captures individuals' commitments to represent disadvantaged groups. Early efforts employed roll-call votes to examine the link between descriptive and substantive representation. However, in settings where party discipline is strong, roll-call votes hardly capture individual efforts related to group representation. Prior studies have therefore explored legislative tools at earlier stages of the policy-making process or more individualized forms of legislative activities that allow the examination of 'acting for' in Pitkin's (1967) sense (for example, Carnes and Lupu 2015; Grose 2011; Minta 2009; Rocca and Sanchez 2007). Among them are plenary debates (Proksch and Slapin 2012), private members' bills (Bräuninger, Brunner and Däubler 2012) and parliamentary questions (Martin and Rozenberg 2012). In particular, parliamentary questions and interpellations can be understood as closed instruments of policy statements, since they are directed at a certain addressee such as a government member, entail a detailed policy question, and require a specific answer (Keh 2015). Closed instruments such as parliamentary questions are thus more suitable to identify specific constituent demands such as disadvantaged interests than open instruments, such as plenary speeches, which typically lack a specific addressee. Thus parliamentary questions (or being the 'first signatory' of a collective parliamentary question) and interpellations are suitable instruments for measuring the extent to which MPs represent different societal groups (Martin 2011a; Martin 2011b; Saalfeld and Bischof 2013).

In our study, we use a particular form of parliamentary questions (Grosse Anfragen/ Kleine Anfragen - minor and major interpellations). While any parliamentary party group or 5 per cent of all MPs can ask such questions, this instrument is mainly used by opposition parties. Minor and major interpellations have to be answered in written form by the federal government. Whereas major interpellations might be discussed in the plenum, this is generally not the case for minor interpellations. The latter are mostly used to monitor government actions by requesting written information about specific issues (Breunig and Schnatterer 2016). Our sample contains only interpellations authored and signed by a group of individual MPs. According to a senior civil servant from the Bundestag parliamentary services (Interview March 2018), the signing of parliamentary questions can be regarded as an individual representative act that is not subject to party group pressure, which allows us to derive individual preferences from these questions. The number of parliamentary questions in a certain policy field indicates the level of interest among parliamentarians in that issue.

We investigate whether MPs who represent disadvantaged groups are more active in grouprelated policy issues. Our sample therefore contains all Bundestag members and their individual interpellations coded by policy domain related to disadvantaged groups. Obviously, representatives of disadvantaged groups do not necessarily speak in favor of the group they represent, but may take up restrictive arguments (Aydemir and Vliegenthart 2016). Our data simply distinguish between remaining silent and choosing to speak on a substantive policy issue for a particular group.

\section{Defining Group Interests in Parliamentary Questions}

A second core challenge associated with the study of group representation is identifying the relevant policy areas that capture the interests of disadvantaged groups. The appropriate demarcation of policy areas is a controversial issue in the gender literature, and there are multiple definitions of 'women's interests' (for a summary, see Childs and Krook 2009). We adopt a simple distinction 
based on topics that we classify as either being about a topic related to the disadvantaged or not (see Swers 2002 for a similar approach regarding gender, or Wüst 2014 for migration). This linkage enables us to pair parliamentary questions with MPs' descriptive features. Our classification is based on observable, material interests in policy making in the respective areas; that is, issues related to sexual harassment are coded as women's issues, and questions about racial discrimination as migration issues. We thus focus on topics for which the link to the respective disadvantaged group is clear and rather narrowly defined.

Parliamentary questions and their content are part of the German Policy Agendas data (Breunig and Schnatterer 2016). The Bundestag provides access to all parliamentary activities including detailed information about questions (title and content), authors and processes via the DIP (Dokumentations - und Informationssystem für Parlamentarische Vorgänge (Parliamentary Material Information System)). The German Policy Agendas team coded all parliamentary questions according to the Comparative Agendas codebook. The coding system places each question in a mutually exclusive and exhaustive policy domain using a semi-supervised learning algorithm. Data and topic coding are then verified by human coders. Table 1 summarizes the policy content of each domain studied. We selected all topics that focus on the interests of the disadvantaged group in question. ${ }^{8}$ The hierarchical topic coding enables us to categorize all topics related to disadvantaged groups into four policy domains. In a second step, we identified interpellations with individual authors and parsed them from each of those questions. Doing so provides us with a measure of parliamentary activity on a given policy issue for each MP.

A brief description of our dataset offers some context about parliamentary questions on disadvantaged groups in the Bundestag. The sample contains 1,277 representatives. We measure their legislative activity on a quarterly basis, which generates 39,392 observations. In our sample, MPs vary in legislative activity in general, and their activity related to disadvantaged groups in particular, in three main ways. First, the number of parliamentary questions varies widely across MPs. While some MPs are very active and ask up to 113 questions per legislative quarter, many ask no questions at all. Secondly, the number of disadvantaged-related questions ranges from twenty-eight group-related questions within a three-month period by an MP from the left-wing party Die Linke, Ursula Jelpke, to no questions whatsoever. Thirdly, the degree to which MPs focus solely on particular minority rights varies: some MPs, such as Ms Jelpke, ask 56 per cent of their parliamentary questions on topics related to disadvantaged groups; likewise, MP Sevim Dagdelen asked 59 per cent of her questions on migration. Questions in this policy area include demands for exact statistics on the number of race-related crimes or regular demands for the exact number of refugees living in Germany. In contrast, the previously mentioned MP Ekin Deligöz, who has a Turkish background and joined the Bundestag at the age of 27, refrained from asking migration-related questions and instead concentrated on issues related to young people. Her questions are characterized by a desire to help young people find employment and to support young people with European exchange and education programs. This MP could have chosen to represent women, ethnic minorities or young people, and thus serves as a perfect example of intersectionality (Hughes 2011). Her case also shows that identifying several disadvantaged groups and including all MPs in the sample is an important feature of this study.

\section{Disadvantaged Groups in Comparison}

Prior studies on representing disadvantaged groups have focused on one group at a time. While some studies focus on the substantive representation of women, others emphasize the representation of social classes or workers. We believe this fragmentation is unfortunate, as the underlying

\footnotetext{
${ }^{8}$ We tested the robustness of the coding scheme and ran models with slightly different specifications of the topics (e.g., excluding 1303 from the age category). We also excluded the general civil rights category (200). Our results remain the same.
} 
Table 1. Descriptive features and policy content according to the comparative agendas coding scheme

Group

concept

Gender

Migration

Social class
Policy content

200 general civil rights and liberties; 202 gender and sexual orientation discrimination; 332 infants and children; 508 parental leave and childcare; 1,208 family issues; 1,308 social benefits related to children 200 general civil rights and liberties; 201 ethnic minority and racial group discrimination; 230 immigration and refugee issues; 529 foreign workers and farm labor issues

302 insurance reform, availability and cost; 335 prescription drug coverage and costs; 336 other or multiple benefits and procedures; 500 general labor and employment; 501 worker safety and protection; 502 employment training and workforce development; 503 employee benefits; 504 employee relations and labor unions; 505 fair labor standards; 506 youth employment; 603 education of underprivileged students; 1,302 poverty and assistance for low-income families; 1,406 low- and middle-income housing programs and needs; 1,409 housing assistance for homeless and homeless issues

Age $\quad 200$ general civil rights and liberties; 204 age discrimination; 205 handicap or disease discrimination; 508 parental leave and child care; 1,206 juvenile crime and the juvenile justice system; 1,303 elderly issues and elderly assistance programs; 1,308 social benefits related to children

Note: all topics are listed according to the German Policy Agendas codebook (Breunig and Schnatterer 2019).

theoretical mechanism can be comparable across all disadvantaged groups. ${ }^{9}$ Therefore, we study four groups in parallel: women, low social class, young and migrants. These groups are the most widely discussed in the literature and range from tiny groups, such as immigrant-origin representatives, to rather sizable social groups (women in parliament). Importantly, all these groups are disadvantaged and under-represented in the legislature as a proportion of the population.

We operationalize these groups as follows. Female representation is coded as the presence of women in the legislature; information on MPs' gender is available on the Bundestag's website. The percentage of female MPs varies from 31 to 34 per cent in our period of study. We define young members of parliament as 35 years old or less (see Kissau, Lutz and Rosset 2012 for a similar definition). Again, information about MPs' age is available online. Approximately 2-3.5 per cent of MPs are under 36. We follow a broad consensus in the legislative literature (for example, Carnes and Lupu 2015; Hout, Brooks and Manza 1995; Weeden and Grusky 2005) and use occupation to capture social class. While the information on occupations prior to entering the Bundestag is not very detailed, we code craftsmen and merchants as having a 'low occupation'. The job profiles were taken from the biographical handbook of the Bundestag (the Kürschners Volkshandbuch Deutscher Bundestag). During our study period, 3.6-7.5 per cent of MPs belong to a lower social class. We validate this classification with an alternative measure of the social occupation status of each parliamentarian using the International Socio-Economic Index of occupational status (ISEI) (Ganzeboom, De Graaf and Treiman 1992; Ganzeboom and Treiman 2010). This measure captures the highest occupational status an MP held before entering parliament. It is an established measure for grouping national occupational classifications and the attractiveness of a profession to a common coding. This measure leads to similar results as our proxy of profession (see Appendix Table 2 and Figure A2_1).

Following Wüst (2014), we code immigrant origin according to two criteria: birth outside Germany and the exclusive acquisition of a citizenship other than German at birth. We also

\footnotetext{
${ }^{9}$ This is not to say that we deny any differences between disadvantaged groups. Philips (1995), for example, stresses that ethnicity is a more heterogeneous group than gender. Heterogeneity among groups varies by context. First, Philips' claim with regard to ethnicity is more pertinent in the US context than for the case we study, Germany. Our empirical measure of visible migrant background limits the heterogeneity considerably. Secondly, Philips argues that social class is built into the party system and that the representation of low social class thus differs qualitatively from gender issues. In our view, this argument applies more to the period studied by Philips than to our timeframe. Given the stark decline of union members in parliament and government, class prominence has at least descriptively changed dramatically in recent periods and is also qualitatively different now. In sum, we believe the underlying mechanism is comparable for all groups considered here: a few representatives working on behalf of (and in the interest of) a larger group in society.
} 
apply these criteria to the parents of each MP. We limit this group to 'visible' immigrants (Bloemraad and Schönwälder 2013; Wüst 2014) derived from the Canadian definition of visible minorities as being 'non-Caucasian or non-white'. The results remain robust if we employ a broader definition and take all MPs with a migrant background into account (see Appendix Table A1). We classify parliamentarians with dark skin color, of Asian or Arabic origin including Turkey, as visible minorities. Wüst (2014) argues that 'while this classification might be misleading in one or the other case [...] it is considered to be a useful approximation to the degree of ethno-cultural difference between immigrant-origin politicians and native Germans'. These differences are likely to have contributed to the higher degrees of discrimination experienced. The share of MPs with a migration background rose from 0.6 per cent in 1998 to 2 per cent in 2013.

\section{Estimation}

To estimate the role of descriptive features and seniority on parliamentary behavior, we need to consider four estimation issues: functional form, autocorrelation, heteroscedasticity across units and contemporaneous correlation, as well as model specification. First, our dependent variables consist of the number of parliamentary questions asked by each MP per quarter. Therefore, we utilize a regression model for count data. Specifically, we use a negative binominal regression because of overdispersion (Cameron and Trivedi 2013; Long 1997). Some initial $\chi^{2}$ tests confirm that a Poisson model is inappropriate in our case.

Secondly, there is a danger of time dependencies in our data because individual MPs are asking questions at regular intervals. Accounting for autocorrelation in count models has received some attention in political science (Brandt et al. 2000; Carter and Signorino 2010). Using a lagged dependent variable implies a growth rate model and potentially leads to estimation problems due to separation. Therefore, we opt to include a cubic spline for the time dimension in order to abate autocorrelation.

Thirdly, our data structure is essentially in time-series cross-sectional form. Given that MPs might be exposed to similar exogenous shocks that might affect them similarly at the same time, we take this possibility into account and use robust standard errors.

Fourthly, we employ two model specifications in the following fashion. In the first version, all covariates enter the model linearly. The second set of models includes an interaction term between descriptive MP features and seniority. Across different forms of descriptive representation, we use the following model specification:

$$
Y_{i t}=\alpha+\beta D_{i t}+\gamma X_{i t}+\delta E_{t}+\sum_{k=1}^{3} \theta_{k}(t)^{k}+\varepsilon
$$

where $i$ is the identifier for each MP and $t$ are quarters. $Y$ is the number of asked questions; $D$ are the descriptive attributes of an MP (and their interaction with seniority in the second set of models); $X$ are controls, including party position, direct mandate and coalition membership; $E$ is an election time dummy, and $t^{k}$ are the cubic splines.

Our models include four controls that pick up alternative strategies to securing a parliamentary mandate. The first control taps into an MP's electoral connections. We control for parliamentarians who are directly elected in their constituencies, as these MPs might feel more obliged to represent their constituency than those elected via a party list (Ohmura 2014; Sieberer 2010; Stoffel 2014). Secondly, holding a position as minister or in the party administration might reduce the number of questions an individual MP asks; therefore, we introduce the variable Ministerial/Party Position. This variable measures whether the MP held a ministerial position (including junior minister), whether he/she was president or vice president of the parliament or committee/deputy chairperson, or whether the MP was involved in the party leadership 
(party leader or secretary of the parliamentary party group). Thirdly, we introduce a control for the election cycle (Election Year) to control for campaign dynamics that might also affect MPs' behavior. A final control, Member of Governing Party, identifies party-specific effects particularly whether an MP has different means at his or her disposal to influence policy making. We include this control because MPs have been shown to ask fewer questions when their party is in government (Wüst 2014). ${ }^{10}$

We utilized marginal effects plots based on estimates of the average effect in the population (Hanmer and Ozan Kalkan 2013) to illustrate the substantive predictions of our models.

\section{Results}

We present our estimation of the additive and interaction models separately in two tables. Table 2 displays our estimates for each disadvantaged group on the number of parliamentary questions. It presents separate models for each group - gender, migrant background, low social class and young - and their corresponding parliamentary questions.

The first lines of Table 2 show the estimated effect for MPs from each disadvantaged group. The estimated coefficient is positive for all four models. The estimates are statistically significant in three of them. We find that being a female parliamentarian is associated with a higher probability of asking questions related to gender issues. Similarly, MPs of migrant descent more likely to ask migration-related questions, and young MPs are more likely to ask age-related questions. However, we do not find that MPs who belong to a lower social class are more likely to ask class-related questions in parliament. Taken together, these estimates suggest that MPs from disadvantaged groups engage in more legislative activities than their counterparts without such a background. These findings imply that descriptive representation results in substantive representation.

The control variables largely perform as expected, but several estimates are not statistically different from zero, such as a lower predicted probability for MPs who are members of a governing party. In election years, MPs tend to ask fewer questions related to disadvantaged groups compared to the rest of the legislative period. Most estimates of the remaining variables are close to (and often statistically indistinguishable from) zero.

Next, we examine the central argument of the article: whether MPs with a disadvantaged background reduce their engagement in group-related policy issues during the course of their legislative career. Table 3 reports the estimated effects for the interaction between belonging to a disadvantaged group and seniority. Again, we parse each group for comparison. To ease interpretation of the interaction effects, we present figures that visualize the estimated marginal effects for members of the disadvantaged groups and their counterparts over time (Figure 1).

We have hypothesized that for disadvantaged groups such as female, young, migrant and low social class, the incentives to represent descriptive interests decrease during the course of a career in parliament. The estimated coefficients in Table 3 suggest that this relationship holds for MPs of immigrant origin as well as young and to some extent also for low social class MPs. The marginal effects plots presented in Figure 1 clearly show this diminishing estimated effect of group representation. In general, the predicted number of questions on group issues declines over the course of an MP's career with a disadvantaged background. However, the marginal effects across the four minority groups (Figure 1) display four interesting variations on this trend.

\footnotetext{
${ }^{10} \mathrm{By}$ introducing this control, we capture party-specific effects as well. A separate introduction of party dummies is thus no longer warranted. Running alternative models, including party dummies instead of the more substantive incumbent party variable, does not alter our results (see Appendix).
} 
Table 2. Negative binomial regression to explain parliamentary questions

\begin{tabular}{|c|c|c|c|c|c|c|c|c|}
\hline & \multicolumn{2}{|c|}{ Gender related } & \multicolumn{2}{|c|}{ Migration related } & \multicolumn{2}{|c|}{ Social class related } & \multicolumn{2}{|c|}{ Age related } \\
\hline & Coef. & s.e & Coef. & s.e & Coef. & s.e & Coef. & s.e \\
\hline MP Gender & 0.30 & $0.04^{\star \star}$ & & & & & & \\
\hline (Visible) Migrant MP & & & 1.26 & $0.12^{\star \star}$ & & & & \\
\hline Low Social Class MP & & & & & 0.05 & 0.09 & & \\
\hline Young MP (<35) & & & & & & & 0.21 & $0.07^{\star \star}$ \\
\hline Seniority & -0.00 & 0.00 & 0.00 & $0.00^{\star}$ & -0.00 & $0.00^{\star}$ & -0.00 & $0.00^{\star}$ \\
\hline Ministerial/Party Position & -0.12 & 0.07 & 0.06 & 0.07 & -0.13 & $0.06^{\star}$ & -0.15 & $0.06^{\star}$ \\
\hline Direct Mandate MP & -0.63 & $0.07^{\star \star}$ & 0.42 & $0.06^{\star \star}$ & -0.48 & $0.06^{\star \star}$ & -0.62 & $0.07^{\star \star}$ \\
\hline Election Year & -0.80 & $0.06^{\star \star}$ & -0.42 & $0.06^{\star \star}$ & -0.68 & $0.05^{\star *}$ & -0.43 & $0.07^{\star \star}$ \\
\hline Member Coalition Party & -2.68 & $0.06^{\star \star}$ & -2.85 & $0.06^{\star \star}$ & -2.67 & $0.04^{\star *}$ & -2.86 & $0.05^{\star \star}$ \\
\hline Cubic Spline 1 & 0.08 & $0.01^{\star \star}$ & 0.02 & 0.02 & 0.11 & $0.01^{\star \star}$ & 0.07 & $0.01^{\star \star}$ \\
\hline Cubic Spline 2 & -0.01 & 0.06 & -0.05 & 0.08 & -0.30 & $0.05^{\star \star}$ & 0.01 & 0.06 \\
\hline Cubic Spline 3 & -0.43 & $0.16^{* *}$ & 0.19 & 0.21 & 0.51 & $0.14^{\star *}$ & -0.42 & $0.16^{\star \star}$ \\
\hline Cubic Spline 4 & 1.20 & $0.19^{\star \star}$ & -0.11 & 0.24 & 0.10 & 0.17 & 1.11 & $0.20^{\star \star}$ \\
\hline Constant & -15.28 & $2.06^{\star \star}$ & -5.05 & 2.62 & -17.40 & $1.93^{\star \star}$ & -12.11 & $2.02^{\star \star}$ \\
\hline Ln Alpha & 0.42 & 0.07 & 1.79 & 0.04 & 0.98 & 0.04 & 0.69 & 0.06 \\
\hline Alpha & 1.53 & 0.10 & 5.99 & 0.25 & 2.65 & 0.11 & 2.00 & 0.12 \\
\hline$N$ & 39,392 & & 39,392 & & 39,392 & & 39,392 & \\
\hline Pseudo $R^{2}=$ & & 0.23 & & 0.15 & & 0.18 & & 0.22 \\
\hline Log pseudolikelihood & $-9,608.44$ & & $-11,891.78$ & & $-15,788.18$ & & $-10,496.60$ & \\
\hline
\end{tabular}

Note: ${ }^{\star *} \mathrm{p}<0.01,{ }^{*} \mathrm{p}<0.05$

Table 3. Negative binomial regression to explain parliamentary questions (interaction models)

\begin{tabular}{|c|c|c|c|c|c|c|c|c|}
\hline & \multicolumn{2}{|c|}{ Gender related } & \multicolumn{2}{|c|}{ Migration related } & \multicolumn{2}{|c|}{ Social class related } & \multicolumn{2}{|c|}{ Age related } \\
\hline & Coef. & s.e. & Coef. & s.e. & Coef. & s.e. & Coef. & s.e. \\
\hline MP Gender & 0.26 & $0.07^{\star \star}$ & & & & & & \\
\hline (Visible) Migrant MP & & & 2.31 & $0.18^{\star \star}$ & & & & \\
\hline Low Social Class MP & & & & & 0.20 & 0.14 & & \\
\hline Young MP (<35) & & & & & & & 0.60 & $0.12^{\star \star}$ \\
\hline Seniority & 0.00 & 0.00 & 0.00 & 0.00 & 0.00 & $0.00^{\star}$ & 0.00 & 0.00 \\
\hline Interaction Minority_Seniority & 0.00 & 0.00 & -0.07 & $0.01^{\star \star}$ & -0.01 & 0.01 & -0.03 & $0.01^{\star \star}$ \\
\hline Ministerial/Party Position & -0.12 & 0.07 & 0.06 & 0.07 & -0.13 & $0.06^{\star}$ & -0.15 & $0.06^{\star}$ \\
\hline Direct Mandate MP & -0.63 & $0.07^{\star \star}$ & 0.43 & $0.07^{\star \star}$ & -0.48 & $0.06^{\star *}$ & -0.62 & $0.07^{\star \star}$ \\
\hline Election Year & -0.80 & $0.06^{\star \star}$ & -0.41 & $0.06^{\star \star}$ & -0.68 & $0.05^{\star *}$ & -0.42 & $0.07^{\star \star}$ \\
\hline Member Coalition Party & -2.68 & $0.06^{\star \star}$ & -2.87 & $0.06^{\star \star}$ & -2.67 & $0.04^{* *}$ & -2.87 & $0.05^{\star \star}$ \\
\hline Cubic Spline 1 & 0.08 & $0.01^{\star \star}$ & 0.02 & 0.02 & 0.10 & $0.01^{\star *}$ & 0.07 & $0.01^{\star \star}$ \\
\hline Cubic Spline 2 & -0.01 & 0.06 & -0.05 & 0.08 & -0.30 & $0.05^{\star \star}$ & 0.00 & 0.06 \\
\hline Cubic Spline 3 & -0.43 & $0.16^{\star \star}$ & 0.20 & 0.21 & 0.50 & $0.14^{\star \star}$ & -0.39 & $0.16^{\star}$ \\
\hline Cubic Spline 4 & 1.20 & $0.19^{\star \star}$ & -0.13 & 0.24 & 0.11 & 0.17 & 1.06 & $0.20^{\star \star}$ \\
\hline Constant & -14.98 & $2.06^{\star \star}$ & -5.03 & 2.63 & -17.33 & $1.92^{\star \star}$ & -12.28 & $2.02^{\star \star}$ \\
\hline Ln Alpha & 0.43 & 0.07 & 1.78 & 0.04 & 0.98 & 0.04 & 0.70 & 0.06 \\
\hline Alpha & 1.53 & 0.10 & 5.92 & 0.24 & 2.65 & 0.11 & 2.01 & 0.12 \\
\hline$N$ & 39,392 & & 39,392 & & 39,392 & & 39,392 & \\
\hline Pseudo $R^{2}=$ & & 0.28 & & 0.15 & & 0.18 & & 0.22 \\
\hline Log pseudolikelihood & $-9,608.19$ & & $-11,877.77$ & & $-15,787.21$ & & $-10,482.37$ & \\
\hline
\end{tabular}

Note: ${ }^{\star \star} p<0.01,{ }^{\star} p<0.05$

First, MPs of immigrant origin are estimated to ask more questions related to migration issues when they are newcomers in parliament; this effect shrinks for MPs with more seniority. According to our estimation, close to the end of their second term (that is, after roughly 7 years in parliament), MPs with a migrant background are no longer more likely to ask questions about migration than other MPs. Given the high quorum of 5 per cent of MPs and the fact that they have to sign in person, asking one question per quarter (that is, four per year) at the beginning of their career seems quite substantial and is a clear sign of representing disadvantaged 

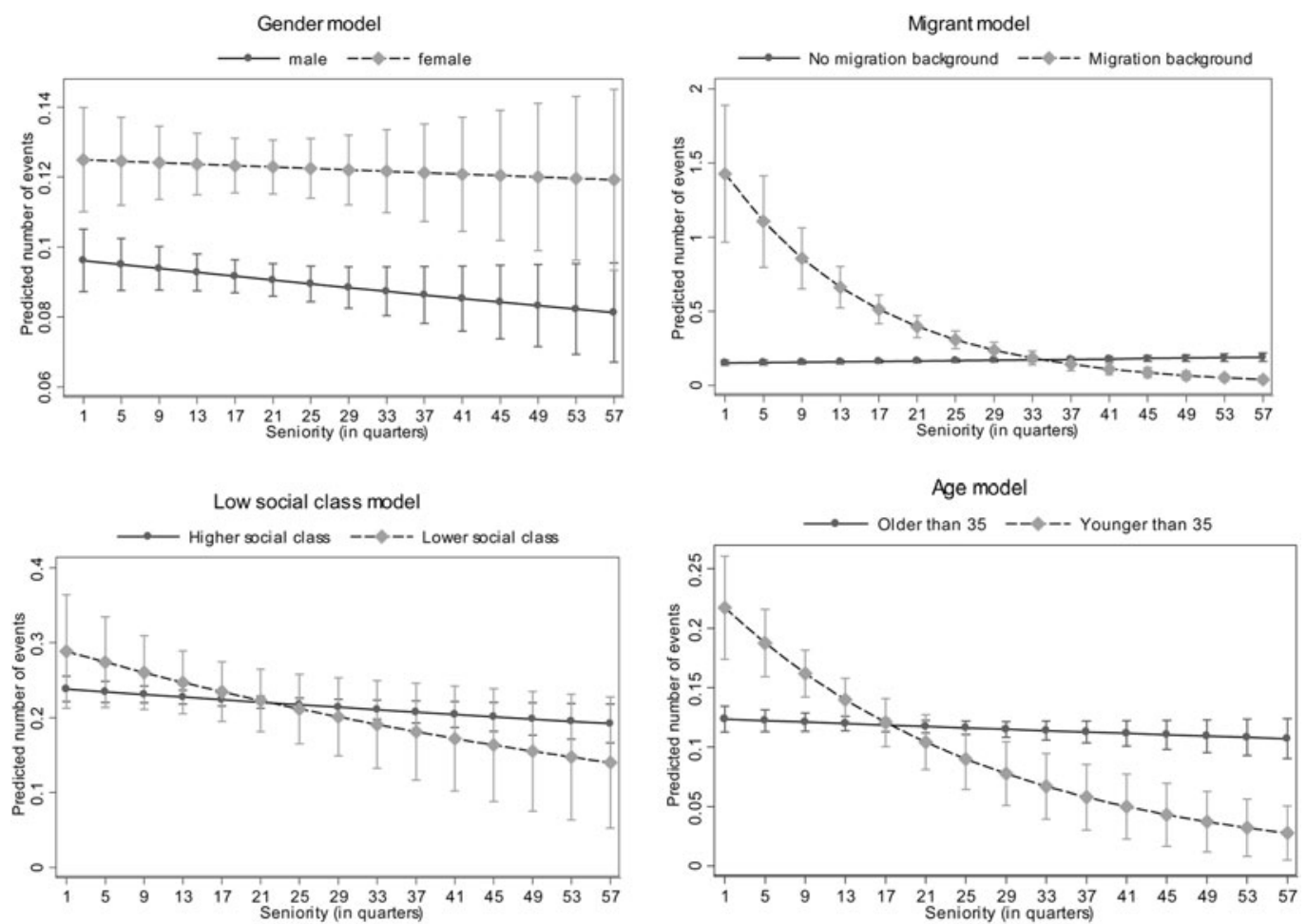

Figure 1. Marginal effects of belonging to a disadvantaged group and seniority (individual minorities) Note: based on Table 3, Models 1-4. Seniority (x-axis) is measured with quarters. It ranges from zero to approximately 15 years of experience.

groups. However, this probability drops quite drastically to only 0.1 question per quarter or one question every three years.

Secondly, the marginal effects for age-related questions suggest that young MPs ask more questions on this topic than their older counterparts during their first term. This enthusiasm is quickly reduced thereafter. Of course, the right tail is very lightly populated as there are very few senior MPs under age 35, so the interpretation of estimated effects should concentrate on the left tail (seniority up to 10 years, or 40 quarters).

Thirdly, the decreasing effect of seniority is equally visible for low-social-class MPs, although it is less distinctive than for the previous two groups. This finding is in line with Carnes (2013), ${ }^{11}$ who reports equally non-significant results in an analysis of working-class congressmen's ideology over time. One potential explanation could be that higher-social-class legislators also occasionally address issues related to poverty because the topic is part of a larger debate on the welfare state and is integrated into broader themes of political competition. Alternatively, it might be easier to stop standing up for your disadvantaged group if you know that others still do.

Fourthly, while patterns are similar for migrant, low-social-class and age-related issues, the estimated effects of gender appear to be on a distinct trajectory. Women are estimated to ask a fairly steady number of questions related to gender issues over their career. They remain consistently above their male counterparts. This finding corresponds to previous research (see, for example, Lowande, Ritchie and Lauterbach 2019; Öhberg and Wängnerud 2013). This could

\footnotetext{
${ }^{11}$ Carnes $(2013,49-53)$ shows descriptive statistics of how the ideology (NOMINATE scores) of legislators from a working-class background changes during their career. While not directly comparable to our analyses, the results similarly show a negative but non-significant effect over time.
} 
be because women are not strictly a minority, since they constitute half of the population. Given this potentially powerful status, it might thus be that women just keep on fighting for their rights. Importantly, the large confidence bounds for senior women also suggest that the variation is large in this group. In other words, while some women keep on representing the under-represented group of women, others give up and cease to ask questions related to gender. This variation could also be linked to contextual factors, such as membership in women's organizations for some women, different degrees of room for women's interests on the party agenda, or the increasing institutionalization of women's issues (Wängnerud 2015). ${ }^{12}$

We have no specific expectations for MPs without a disadvantaged background. Our estimated marginal effects indicate that these legislators generally ask fewer questions related to disadvantaged groups, and that their behavior remains consistent during their parliamentary career, so we observe no career effects.

All of our findings are robust to alternative specifications. We conducted four robustness checks, which involved estimating models with: (1) a different operationalization of immigrant origin (Appendix Table A1); (2) a different operationalization of low social class (Appendix Table A2); (3) party dummies (Table A3); (4) excluding first-term MPs (Table A4), and (5) a different operationalization of questions related to disadvantaged groups (Table A5). None of these different measures or alternative specifications substantively changes our results.

In sum, we find twofold support for our hypotheses. First, our estimation results lend further evidence to earlier studies: representatives of disadvantaged groups tend to be more concerned about topics related to their group and thus represent substantive group interests. Except for MPs coming from a low social class, this tendency is statistically significant for women, young and immigrant-origin parliamentarians.

Secondly and importantly, the incentives to focus on group-related issues diminish over the course of a parliamentary career. Across our models, we find the expected negative trend to focus on group issues over time. The estimations show that representing disadvantaged groups and their policy concerns is not constant over the course of a career. Hence, it is important to theorize about individuallevel incentives that lead MPs to focus on certain issues at different stages of their career. Once individual strategic choices are apparent, we can model the collective effects of descriptive representation on substantive interest representation. After all, the effect of descriptive representation of disadvantaged groups does not follow automatically from their sheer presence in parliament.

\section{Conclusion}

In this article, we study how the descriptive representation of disadvantaged groups in parliament relates to advances in substantive representation. Our main argument is that this link is far from automatic and constant, and that a closer look at representatives' individual motivations is warranted. We argue that legislators' motivation to engage in policy domains related to their descriptive traits is career dependent. MPs from disadvantaged groups have a particular incentive to engage in group representation when they are newcomers in parliament, but this incentive declines as they become more senior. This decrease in individual incentives and motivation to represent group issues has important consequences for the link between descriptive and substantive representation. Given the differences in individual career trajectories, we do not observe a straightforward link between enhanced descriptive to greater substantive representation. Instead, the linkage depends on the career advancement of individual group representatives. Significant substantive representation occurs in the early stages of parliamentary careers but diminishes substantially when MPs serve for a long time in parliament.

In this article, we are able to generalize our findings across different disadvantaged groups. So far, the literature on group representation has developed independently for each disadvantaged

\footnotetext{
${ }^{12} \mathrm{We}$ thank a reviewer for pointing out these potential context factors.
} 
group. For example, a specialized literature on female representation progresses in parallel to and separately from a renewed focus on the representation of lower social classes. We acknowledge that individual legislators are often able to advocate on behalf of different disadvantaged groups, and therefore approach group representation from a comparative viewpoint. This inclusion allows us to develop a general argument about descriptive representation and to broaden the empirical study of representing the disadvantaged.

Even among our selection of disadvantaged groups, we acknowledge that various disparities among them might exist and could affect their representative function. For example, the size of a group might affect the incentives to represent them or the degree of interest cohesion within the group. The literature on female descriptive representation and the emphasis on 'critical mass' or role models could be a good starting point for further discussion. Another distinction could be whether people are able to leave behind their identity as a representative of a disadvantaged group. This transformation is certainly less challenging for low-social-class or young MPs than for women and those with a visible migrant background.

In our analysis, we utilized parliamentary questions as an important avenue for expressing individual policy activity. While this measure has several advantages, which we discussed above, the downside of our measure may be its tentative policy impact. Future work on other legislative activities with more directly observable outcomes should aim to corroborate our findings. The dilemma associated with identifying individual legislative accomplishments in democratic settings is of course that almost all binding decisions are passed by a collective. Given this constraint, it might be more fruitful to explore the content of parliamentary questions and other legislative activities in more detail. Examining the specific content of parliamentary questions might reveal subtler ways of representing the interests of the disadvantaged. For example, legislators with a disadvantaged background can advance group interests by intervening in core government functions such as welfare or education. In sum, our argument connects the link between descriptive and substantive representation to MPs' individual motives. Taking career motives into account offers a new and dynamic perspective on an important topic in political science and society at large. If anything, our argument offers a potential explanation for a number of diverse findings on the fragile link between descriptive and substantive representation.

Supplementary material. Online appendices are available at https://doi.org/10.1017/S0007123420000642.

Acknowledgements. This study has profited from feedback at various conferences (EPSA, ECPR, CAP and SPSA conferences, Amsterdam Centre of Inequality Research seminar, Opening Conference of the Cluster of Excellence 'The Politics of Inequality', final conference for the NCCR Democracy) and in particular from comments by Miriam Hänni, Simon Hix, Julien Navarro, Didier Ruedin, Pascal Sciarini, Guido Tiemann, Denise Traber and Samuel Workman. We thank Katharina Barsch, Jana Rhyner, Sean Burgess for excellent research assistance and Tomas Turner-Zwinkels for the ISEI data.

Financial support. Parts of the data collection were funded by the SNF-funded project 'Parliamentary Careers in Comparison' (No 100017L_162427, PI: Stefanie Bailer), the SNF-funded project 'Inequality in the mind' (100017_178980, PI: Nathalie Giger), the ERC project 'Unequal Democracies' (No 741538, PI: Jonas Pontussson) and the DFG-funded Project 'Conditional Responsiveness in Germany and France' No 281515512, PI: Christian Breunig) and a Volkswagen Foundation funded project ('Migrants as political actors', No II/81749, PI: Andreas M. Wüst). Breunig carried out research as visiting fellow at the LMU's Center for Advanced Studies for this study.

Data Availability Statement. Replication data for this paper can be found in Harvard Dataverse at: https:/doi.org/10.7910/ DVN/SZGS68.

\section{References}

Aydemir N and Vliegenthart R (2016) 'Minority representatives' in the Netherlands: supporting, silencing or suppressing? Parliamentary Affairs 69, 73-92.

Bailer S and Ohmura T (2017) Exploring, maintaining, and disengaging - the three phases of a legislator's life. Legislative Studies Quarterly 43(3), 493-520.

Bartels LM (2009) Unequal Democracy: The Political Economy of the New Gilded Age. Princeton, NJ: Princeton University Press. 
Best H and Vogel L (2014) The sociology of legislators. In Martin S, Saalfeld T and Strom K (eds), The Oxford Handbook of Legislative Studies. Oxford: Oxford University Press, pp. 57-81.

Bird K (2003) Who are the women? Where are the women? And what difference can they make? Effects of gender parity in French municipal elections. French Politics 1, 5-38.

Bird K, Saalfeld T and Wüst AM (2010) The Political Representation of Immigrants and Minorities: Voters, Parties and Parliaments in Liberal Democracies. London: Routledge.

Bloemraad I and Schönwälder K (2013) Immigrant and ethnic minority representation in Europe: conceptual challenges and theoretical approaches. West European Politics 36, 564-579.

Bolzendahl C (2014) Opportunities and expectations. The gendered organization of legislative committees in Germany, Sweden, and the United States. Gender and Society 28(6), 847-876.

Brandt PT, et al. (2000) Dynamic modeling for persistent event-count time series. American Journal of Political Science 44, 823-843.

Bratton KA and Ray LP (2002) Descriptive representation, policy outcomes, and municipal day-care coverage in Norway. American Journal of Political Science 46, 428-437.

Bräuninger T, Brunner M and Däubler T (2012) Personal vote-seeking in flexible list systems: how electoral incentives shape Belgian MPs' bill initiation behaviour. European Journal of Political Research 51, 607-645.

Breunig C and Schnatterer T (2016) German Policy Agendas - Data Set and Intitial Insights. Data Report.

Butler DM (2014) Representing the Advantaged: How Politicians Reinforce Inequality. Cambridge: Cambridge University Press.

Cameron AC and Trivedi PK (2013) Regression Analysis of Count Data, 2nd Edn. Cambridge and New York: Cambridge University Press.

Carnes N (2013) White-Collar Government: The Hidden Role of Class in Economic Policy Making. Chicago, IL: University of Chicago Press.

Carnes N and Lupu N (2015) Rethinking the comparative perspective on class and representation: evidence from Latin America. American Journal of Political Science 59, 1-18.

Carnes N and Lupu N (2016) Do voters dislike working-class candidates? Voter biases and the descriptive underrepresentation of the working class. American Political Science Review 110, 832-844.

Carter DB and Signorino CS (2010) Back to the future: modeling time dependence in binary data. Political Analysis 18, 271-292.

Celis K and Erzeel S (2013) Gender and ethnicity: intersectionality and the politics of group representation in the low countries. Representation 49, 487-499.

Celis K and Wauters B (2010) Pinning the butterfly: women, blue-collar and ethnic minority MPs vis-à-vis parliamentary norms and the parliamentary role of the group representative. Journal of Legislative Studies 16, 380-393.

Celis K, Erzeel S and Mügge L (2015) Intersectional puzzles: understanding inclusion and equality in political recruitment. Politics \& Gender 11, 765-770.

Childs S and Krook ML (2009) Analysing women's substantive representation: from critical mass to critical actors. Government and Opposition 44, 125-145.

Childs S and Lovenduski J (2013) Political representation. In Waylen G, Celis K, Kantola J and Weldon SL (eds), Oxford Handbook of Gender and Politics. Oxford: Oxford University Press, pp. 489-513.

Collet C (2008) Minority candidates, alternative media, and multiethnic America: deracialization or toggling? Perspectives on Politics 6, 707-728.

Dancygier RM et al. (2015) Why are immigrants underrepresented in politics? Evidence from Sweden. American Political Science Review 109, 703-724.

Davidson RH (1969) The Role of the Congressman. New York: Pegasus.

Davidson-Schmich L (2016) Gender Quotas and Democratic Participation: Recruiting Candidates for Elective Offices in Germany. Ann Arbor: University of Michigan Press.

de Jong S and Kimm S (2017) The co-optation of feminisms: a research agenda. International Feminist Journal of Politics 19, $185-200$.

Fenno RF (1962) The House Appropriations Committee as a political system: the problem of integration. American Political Science Review 56, 310-324.

Ganzeboom HBG and Treiman DJ (2010) International Stratification and Mobility File: Conversion Tools. Amsterdam: Department of Social Research Methodology.

Ganzeboom HBG, De Graaf PM and Treiman DJ (1992) A standard international socio-economic index of occupational status. Social Science Research 21, 1-56.

Gilens M (2012) Affluence and Influence: Economic Inequality and Political Power in America. Princeton, NJ: Princeton University Press.

Green-Pedersen C and Mortensen PB (2010) Who sets the agenda and who responds to it in the Danish parliament? A new model of issue competition and agenda-setting. European Journal of Political Research 49(2), 247-281.

Greene Z and O'Brien DZ (2016) Diverse parties, diverse agendas? Female politicians and the parliamentary party's role in platform formation. European Journal of Political Research 55, 435-453. 
Grose CR (2005) Disentangling constituency and legislator effects in legislative representation: black legislators or Black districts? Social Science Quarterly 86, 427-443.

Grose CR (2011) Congress in Black and White: Race and Representation in Washington and at Home. Cambridge: Cambridge University Press.

Hacker JS and Pierson P (2010) Winner-Take-All Politics: How Washington Made the Rich Richer-and Turned Its Back on the Middle Class. New York: Simon \& Schuster.

Hanmer MJ and Ozan Kalkan K (2013) Behind the curve: clarifying the best approach to calculating predicted probabilities and marginal effects from limited dependent variable models. American Journal of Political Science 57, $263-277$.

Hänni M (2017) Presence, Representation, and Impact: How Minority MPs Affect Policy Outcomes. Legislative Studies Quarterly 42, 97-130.

Hawkesworth M (2003) Congressional enactments of race-gender: toward a theory of raced-gendered institutions. American Political Science Review 97, 529-550.

Höhmann D (2019) When do female MPs represent women's interests? Electoral systems and the legislative behavior of women. Political Research Quarterly. https://doi.org/10.1177/1065912919859437.

Homola J (2019) Are parties equally responsive to women and men? British Journal of Political Science 49(3), 957-975.

Hout M, Brooks C and Manza J (1995) The democratic class struggle in the United States, 1948-1992. American Sociological Review, 805-828.

Hughes MM (2011) Intersectionality, quotas, and minority women's political representation worldwide. American Political Science Review, 604-620.

Interparliamentary Union (2016) Women in National Parliaments. http://www.ipu.org/wmn-e/world.htm.

Ismayr W (2012) Der Deutsche Bundestag. Opladen: Leske\&Budrich.

Keh JF (2015) The centralisation of parliamentary policy statements in Western European parliaments. West European Politics 38, 1086-1105.

Kissau K, Lutz G and Rosset J (2012) Unequal representation of age groups in Switzerland. Representation 48, 63-81.

Kittilson MC (2008) Representing women: the adoption of family leave in comparative perspective. The Journal of Politics $\mathbf{7 0 ,}$ 323-334.

Krook ML and O'Brien DZ (2010) The politics of group representation: quotas for women and minorities worldwide. Comparative Politics, 253-272.

Lloren A (2015) Women's substantive representation: defending feminist interests or women's electoral preferences? The Journal of Legislative Studies 21, 144-167.

Long JS (1997) Regression Models for Categorical and Limited Dependent Variables, 1st Edn. Thousand Oaks, CA: SAGE Publications, Inc.

Lowande K, Ritchie M and Lauterbach E (2019) Descriptive and substantive representation in Congress: evidence from 80,000 congressional inquiries. American Journal of Political Science 63(3), 644-659.

Lublin D (1997) The Paradox of Representation: Racial Gerrymandering and Minority Interests in Congress. Princeton, NJ: Princeton University Press.

Mansbridge J (1999) Should Blacks represent Blacks and women represent women? A contingent. Journal of Politics 62 , 628-657.

Mansbridge J (2009) A “selection model" of political representation. Journal of Political Philosophy 17, 369-398.

Mansbridge J (2015) Should workers represent workers? Journal of Politics 21, 261-270.

Martin S (2011a) Parliamentary questions, the behaviour of legislators, and the function of legislatures: an introduction. Journal of Legislative Studies 17, 259-270.

Martin S (2011b) Using parliamentary questions to measure constituency focus: an application to the Irish case. Political Studies 59(2), 472-488.

Martin S and Rozenberg O (2012) The Roles and Function of Parliamentary Questions. London: Routledge.

Minta MD (2009) Legislative oversight and the substantive representation of black and Latino interests in congress. Legislative Studies Quarterly 34, 193-218.

Miquel GPI and Snyder JM (2006) Legislative effectiveness and legislative careers. Legislative Studies Quarterly 31, 347-381.

Mutlu Ö (2016) Politik Ohne Grenzen. Migrationsgeschichten Aus Dem Deutschen Bundestag [Politics without Borders: Migration Stories from the German Bundestag]. Berlin: B\&S Siebenhaar Verlag.

Norris P and Lovenduski J (1995) Political Recruitment - Gender, Race and Class in the British Parliament. Cambridge: University of Cambridge.

O'Brien DZ (2015) Rising to the top: gender, political performance, and party leadership in parliamentary democracies. American Journal of Political Science 59, 1022-1039.

O'Grady T (2019) Careerists versus coal-miners: welfare reforms and the substantive representation of social groups in the British Labour Party. Comparative Political Studies 52(4), 544-578.

Öhberg P and Wängnerud L (2013) Testing the impact of political generations: the class of 94 and pro-feminist ideas in the Swedish Riksdag. Scandinavian Political Studies 37, 61-81.

Ohmura T (2014) When your name is on the list, it is time to party: the candidacy divide in a mixed-member proportional system. Representation 50, 69-82. 
Osborne TL (2012) How Women Represent Women: Political Parties, Gender, and Representation in the State Legislatures. Oxford: Oxford University Press.

Philips A (1995) The Politics of Presence: The Political Representation of Gender, Ethnicity, and Race. Oxford: Oxford University Press.

Pitkin HF (1967) The Concept of Representation. Berkeley: University of California Press.

Preuhs RR (2006) The conditional effects of minority descriptive representation: black legislators and policy influence in the American states. Journal of Politics 68, 585-599.

Proksch S-O and Slapin JB (2012) Institutional foundations of legislative speech. American Journal of Political Science 56, 520-537.

Rocca MS and Sanchez GR (2007) The effect of race and ethnicity on bill sponsorship and cosponsorship in Congress. American Politics Research 36(1), 130-152.

Ruedin D (2009) Ethnic group representation in a cross-national comparison. The Journal of Legislative Studies 15, 335-354.

Ruedin D (2013) Why Aren't They There? The Political Representation of Women, Ethnic Groups and Issue Positions in Legislatures. Colchester: ECPR Press.

Saalfeld T (2011) Parliamentary questions as instruments of substantive representation: visible minorities in the UK House of Commons, 2005-10. The Journal of Legislative Studies 17, 271-289.

Saalfeld T and Bischof D (2013) Minority-ethnic MPs and the substantive representation of minority interests in the House of Commons, 2005-2011. Parliamentary Affairs 66, 305-328.

Schiller WJ (1995) Senators as political entrepreneurs: using bill sponsorship to shape legislative agendas. American Journal of Political Science, 186-203.

Sieberer U (2010) Behavioral consequences of mixed electoral systems: deviating voting behavior of district and list MPs in the German Bundestag. Electoral Studies 29, 484-496.

Siefken ST (2010) Parlamentarische Frageverfahren - Symbolpolitik Oder Wirksames Kontrollinstrument? [Parliamentary questions - symbolic policy or efficient instrument of control] ZParl Zeitschrift für Parlamentsfragen 41, 18-36.

Stoffel MF (2014) MP behavior in mixed-member electoral systems. Electoral Studies 35, 78-87.

Strøm K (1997) Rules, reasons and routines: legislative roles in parliamentary democracies. In Müller WC and Saalfeld T (eds), Members of Parliament in Western Europe. London: Frank Cass, pp. 155-174.

Swers ML (2002) The Difference Women Make: The Policy Impact of Women in Congress. Chicago, IL: University of Chicago Press.

von der Lippe B and Väyrynen T (2011) Co-opting feminist voices for the war on terror: Laura Bush meets Nordic Feminism. European Journal of Women's Studies 18, 19-33.

Wängnerud L (2015) The Principles of Gender-Sensitive Parliaments. New York: Routledge.

Weeden KA and Grusky DB (2005) The case for a new class Map. American Journal of Sociology 111, 141-212.

Wüst AM (2014) A lasting impact? On the legislative activities of immigrant-origin parliamentarians in Germany. The Journal of Legislative Studies 20, 495-515.

Cite this article: Bailer S, Breunig C, Giger N, Wüst AM (2022). The Diminishing Value of Representing the Disadvantaged: Between Group Representation and Individual Career Paths. British Journal of Political Science 52, 535-552. https://doi.org/ $10.1017 /$ S0007123420000642 